\title{
Predicting Liver-Related Events Using Transient Elastography in Chronic Hepatitis C Patients with Sustained Virological Response
}

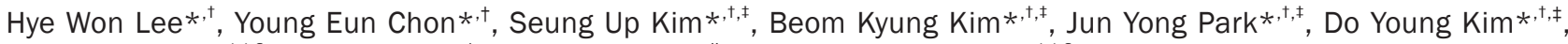 \\ Sang Hoon Ahn ${ }^{,, t, \neq,}$, Kyu Sik Jung ${ }^{*, \dagger}$, Young Nyun Park", and Kwang-Hyub Han ${ }^{*,+,, \S}$ \\ *Department of Internal Medicine, ${ }^{\dagger}$ Institute of Gastroenterology, ${ }^{\ddagger}$ Liver Cirrhosis Clinical Research Center, ${ }^{\S}$ Brain Korea 21 Project for Medical \\ Science, and "Department of Pathology, Yonsei University College of Medicine, Seoul, Korea
}

Background/Aims: Few studies have investigated prognostic factors for the development of liver-related events (LREs) in patients with chronic hepatitis $\mathrm{C}(\mathrm{CHC})$ who achieve sustained virological response (SVR). Methods: We analyzed 190 patients with $\mathrm{CHC}$ who achieved SVR after treatment with pegylated interferon (peg-IFN) plus ribavirin. LREs were defined as any complications related to cirrhosis, hepatocellular carcinoma (HCC), or liver-related mortality. Results: The mean age was 54.1 years, and 84 of the patients (44.2\%) were male. The mean liver stiffness (LS) value at SVR was $7.1 \pm 5.4 \mathrm{kPa}$. During the follow-up period (median, 43.0 months), LREs occurred in 10 patients (5.3\%; HCC in eight patients, ascites in one patient, and liver-related mortality in one patient). By multivariate Cox regression analysis, age, $\alpha$-fetoprotein level, and LS value were independent predictors for LRE development (all $p<0.05$ ). Patients with LS values $\geq 7.0 \mathrm{kPa}$ had a greater risk (hazard ratio, 9.472; 95\% confidence interval, 1.018 to 88.126; $p=0.048$ ) for LRE development compared to those with LS values $<7.0 \mathrm{kPa}$. Conclusions: The LS value at SVR is useful for predicting LRE development in $\mathrm{CHC}$ patients who achieve SVR after treatment with peg-IFN plus ribavirin. Thus, LRE surveillance strategies might be optimized according to the LS values at SVR, even with complete viral eradication. (Gut Liver 2016;10:429436)

Key Words: Hepatitis C, chronic; Carcinoma, hepatocellular; Liver stiffness; Sustained virological response; Transient elastography

\section{INTRODUCTION}

The achievement of a sustained virological response (SVR) to treatment with pegylated interferon (peg-IFN) plus ribavirin is a surrogate for the cure of infection in patients with chronic hepatitis $\mathrm{C}(\mathrm{CHC})$ and regarded as a very important favorable predictor to prevent disease progression. ${ }^{1-4}$ In addition, it is well known that SVR can significantly reduce the risk of the development of liver-related events (LREs), such as hepatocellular carcinoma (HCC), hepatic decompensation, or liver-related death. ${ }^{5,6}$ However, in spite of successful hepatitis C virus (HCV) eradication by antiviral therapy, the risk of LRE development cannot always be alleviated, mainly due to residual advanced fibrosis or cirrhosis. ${ }^{7}$ Thus, the assessment of residual fibrotic burden in patients with CHC who achieve SVR is of paramount importance, not only for prognostication but also for defining an effective surveillance program for the early detection of LRE development, because the degree of liver fibrosis is significantly associated with the risk of LRE development. ${ }^{8}$

SVR can lead to regression of liver fibrosis and cirrhosis., ${ }^{9,10}$ Thus, it can be a routine strategy to perform liver biopsy (LB) to assess the degree of the residual liver fibrosis immediately after achieving SVR. However, this diagnostic approach has not been widely used due to several reasons. First, although LB has been the gold standard to assess the degree of liver fibrosis, LB is an invasive procedure with the rare but potential risk of life-threatening complications. ${ }^{11}$ Second, LB has an inherent sampling error and interpretational variability even among experienced pathologists. ${ }^{12}$ Therefore, the development of a noninvasive tool that can accurately assess the degree of fibrotic burden at SVR can have important clinical implications.

Recently, the measurement of liver stiffness (LS) using tran-

\footnotetext{
Correspondence to: Seung Up Kim

Department of Internal Medicine, Yonsei University College of Medicine, 50 Yonsei-ro, Seodaemun-gu, Seoul 120-752, Korea

Tel: +82-2-2228-1982, Fax: +82-2-393-6884, E-mail: ksukorea@yuhs.ac

Received on January 11, 2015. Revised on April 21, 2015. Accepted on April 23, 2015. Published online September 9 , 2015

pISSN 1976-2283 eISSN 2005-1212 http://dx.doi.org/10.5009/gnl15021

Hye Won Lee and Young Eun Chon contributed equally to this work as first authors.

(c) This is an Open Access article distributed under the terms of the Creative Commons Attribution Non-Commercial License (http://creativecommons.org/licenses/by-nc/4.0) which permits unrestricted non-commercial use, distribution, and reproduction in any medium, provided the original work is properly cited.
} 
sient elastography (TE) has proven a reliable and noninvasive tool in assessing the amount of fibrosis in patients with chronic viral hepatitis. ${ }^{13}$ Based on the accumulated literature, TE has been endorsed by the European Association for the Study of the Liver (EASL) as a noninvasive tool to stage liver fibrosis before commencing antiviral treatment in patients with $\mathrm{CHC}^{14-16}$ In contrast, in a more recent cross-sectional study, ${ }^{17}$ TE showed suboptimal performance in diagnosing cirrhosis at SVR, as a consequence of liver remodeling and fibrosis reabsorption through antiviral therapy. However, it is unknown whether LS measurement using TE can predict long-term outcomes after the achievement of SVR from a longitudinal perspective.

Thus, the aim of our study was to investigate whether LS values obtained using TE at SVR, which reflect the remaining fibrotic burden, can predict LRE development in patients with CHC who achieved SVR after peg-IFN plus ribavirin therapy.

\section{MATERIALS AND METHODS}

\section{Patients}

Patients with CHC who had been treated with peg-IFN plus ribavirin therapy and underwent LS measurement using TE at SVR at Severance Hospital, Yonsei University College of Medicine, Seoul, Korea, between May 2005 and August 2014, were considered eligible. Patients who did not achieve SVR due to following reasons were excluded: (1) nonresponders, (2) relapsers, (3) follow-up loss, or (4) incomplete treatment due to poor compliance or adverse events. Although all the patients achieved SVR, some patients were excluded based on the following exclusion criteria: (1) co-infection with hepatitis B virus or human immunodeficiency virus, (2) other serious concurrent illness (e.g., alcoholism, uncontrolled diabetes, or cancer), (3) hepatic decompensation at enrollment or a prior history of decompensation, (4) HCC at enrollment or a previous history of HCC, (5) unavailable LS measurement or invalid LS values, and (6) follow-up loss or follow-up period less than 6 months after SVR (Fig. 1).
Written informed consent was obtained from all study participants. This study was approved by the independent Institutional Review Board of Severance Hospital (IRB number: 20131030-002) and conformed to the ethical guidelines of the 1975 Helsinki Declaration.

\section{Treatment protocol and follow-up}

Patients were treated with either $180 \mu \mathrm{g}$ peg-IFN- $\alpha 2 \mathrm{a}$ once per week or $1.5 \mu \mathrm{g}$ peg-IFN- $\alpha 2 \mathrm{~b}$ per week. Ribavirin (15 mg/ $\mathrm{kg}$ body weight per day) was given for patients with genotype 1 , and a flat dose of $800 \mathrm{mg}$ was given for patients with genotype 2 or 3. During peg-IFN plus ribavirin therapy, all patients were seen at baseline and then 2 to 4 weeks. At every visit, a complete blood cell count, routine blood chemistry tests, compliance, and adverse events were checked. HCV RNA levels were checked at baseline, at the end of treatment, and at 6 months after the end of treatment. Thereafter, patients visited every 6 to 12 months to monitor the HCV RNA level. Serum HCV RNA levels were quantified using commercial polymerase chain reaction assays (Amplicor HCV or Roche Diagnostics, Seoul, Korea). SVR was defined as the presence of undetectable HCV RNA levels at the end of treatment and at follow-up 6 months after the end of treatment. Serum aspartate aminotransferase and alanine aminotransferase (ALT) levels were measured using standard laboratory procedures with the upper limit of normal set at 40 $\mathrm{IU} / \mathrm{mL}$ for both. During the follow-up period, all patients underwent periodic surveillance with ultrasonography and laboratory work-ups, including checking the level of $\alpha$-fetoprotein (AFP) every 3 or 6 months to screen for HCC and other portal hypertension-related complications. The end of follow-up period was March 2015.

\section{LS measurement using TE}

In all patients, LS measurement using TE was performed when SVR was confirmed. TE examinations were done by a single experienced technician (>20,000 examinations) who was blinded to patient information. Results were expressed in
$256 \mathrm{CHC}$ patients treated with peg-IFN+ribavirin

\begin{tabular}{|c|c|}
\hline$\downarrow$ & $\begin{array}{l}\text { 1) Non-responders } \\
\text { 2) Relapsers } \\
\text { 3) Follow-up loss } \\
\text { 4) Incomplete treatment due to poor compliance } \\
\text { or adverse events }\end{array}$ \\
\hline $\begin{array}{l}234 \mathrm{CHC} \text { patients with } \\
\text { sustained virological response }\end{array}$ & \multirow{4}{*}{$\begin{array}{l}\text { 1) Co-infection with hepatitis B virus or HIV } \\
\text { 2) Other serious concurrent illness } \\
\text { 3) Hepatic decompensation at enrollment or a prior } \\
\text { history of decompensation } \\
\text { 4) HCC at enrollment or a previous history of HCC } \\
\text { 5) Unavailable LS measurement or invalid LS values } \\
\text { 6) Follow-up loss or follow-up period }<6 \text { months after SVR }\end{array}$} \\
\hline & \\
\hline & \\
\hline 190 Patients were finally analyzed & \\
\hline
\end{tabular}

Fig. 1. Recruitment algorithm. A total of 256 patients with chronic hepatitis C (CHC) who were treated with pegylated interferon (pegIFN) and ribavirin were enrolled. of these, 66 patients were excluded based on our exclusion criteria. A final total of 190 patients were selected for statistical analysis. HIV, human immunodeficiency virus; HCC, hepatocellular carcinoma LS, liver stiffness; SVR, sustained virological response. 
kilopascal $(\mathrm{kPa})$, and the median of successful measurements was selected as the representative LS value. The interquartile range (IQR) was defined as an index of intrinsic variability of LS values corresponding to the interval of LS results containing 50\% of the valid measurements between the 25th and 75th percentiles. In this study, only measurements with at least 10 valid shots, a success rate of at least 60\%, and an IQR to median value ratio (IQR/M) of $<0.3$ were considered reliable and used for statistical analysis. ${ }^{18}$

\section{Definition of liver cirrhosis and LREs}

If histological information was not available, clinically diagnosed liver cirrhosis was defined as follows: (1) platelet count $<100,000 / \mu \mathrm{L}$ and ultrasonographic findings suggestive of cirrhosis, including a blunted, nodular liver edge accompanied by splenomegaly (>12 cm); or (2) esophageal or gastric varices. ${ }^{19}$

The primary endpoint was to evaluate whether LS values can predict LRE development in patients with CHC who achieved

Table 1. Baseline Characteristics at Sustained Virological Response $(\mathrm{n}=190)$

\begin{tabular}{|c|c|}
\hline Variable & Value \\
\hline \multicolumn{2}{|l|}{ Demographic variable } \\
\hline Age, yr & $54.1 \pm 11.4$ \\
\hline Male sex & $84(44.2)$ \\
\hline Body mass index, $\mathrm{kg} / \mathrm{m}^{2}$ & $23.6 \pm 3.1$ \\
\hline Diabetes mellitus & $31(16.3)$ \\
\hline Hypertension & $35(18.4)$ \\
\hline \multicolumn{2}{|l|}{ Treatment variable } \\
\hline \multicolumn{2}{|l|}{ HCV genotype } \\
\hline $1 / 2$ or 3 & $109(57.4) / 81(42.6)$ \\
\hline \multicolumn{2}{|l|}{ IFN regimen } \\
\hline Peg-IFN $\alpha-2 a / 2 b$ & $126(66.3) / 64(33.7)$ \\
\hline \multicolumn{2}{|l|}{ Laboratory variable } \\
\hline Alanine aminotransferase, IU/L & $20.3 \pm 15.4$ \\
\hline Serum albumin, $\mathrm{g} / \mathrm{dL}$ & $4.3 \pm 0.4$ \\
\hline Total bilirubin, mg/dL & $0.8 \pm 0.3$ \\
\hline Prothrombin time, INR & $0.9 \pm 0.1$ \\
\hline$\alpha$-Fetoprotein, $\mathrm{ng} / \mathrm{mL}$ & $3.51 \pm 3.8$ \\
\hline Total cholesterol, mg/dL & $164.2 \pm 42.3$ \\
\hline Clinical liver cirrhosis & $85(44.7)$ \\
\hline Child-Pugh score 5/6 & $189(99.5) / 1(0.5)$ \\
\hline \multicolumn{2}{|l|}{ Liver stiffness measurement } \\
\hline Liver stiffness values, $\mathrm{kPa}$ & $7.1 \pm 5.4$ \\
\hline Interquartile range, $\mathrm{kPa}$ & $1.5 \pm 0.8$ \\
\hline Interquartile range/median, \% & $25.2 \pm 17.6$ \\
\hline Success rate, $\%$ & $95 \pm 10$ \\
\hline
\end{tabular}

Data are presented as mean \pm SD or number $(\%)$.

$\mathrm{HCV}$, hepatitis C virus; peg-IFN, pegylated interferon; INR, international normalized ratio; $\mathrm{kPa}$, kilopascal.
SVR. LREs were defined as a cirrhotic complication (ascites, variceal bleeding, spontaneous bacterial peritonitis, hepatic encephalopathy, and hepatorenal syndrome), HCC, and/or liverrelated mortality. If a patient experienced different types of LREs at different time points, we selected only the earliest LRE for statistical analysis.

\section{Statistical analyses}

Data are expressed as the mean \pm standard deviation, median (range), or number (\%) as appropriate. Differences between continuous and categorical variables were examined for statistical significance with Student t-test (or Mann-Whitney test, if appropriate) and chi-square test (or Fisher exact test, if appropriate). Patients were censored at the time of the first presentation of a LRE or at the last follow-up. LRE rates were calculated using the Kaplan-Meier method and were compared with the log-rank test. The Cox proportional hazards model was used for multivariate analyses. Time-dependent areas under the receiver operating characteristic curves (AUROCs) were evaluated to estimate the predictive performance of models for LRE development risk. All statistical analyses were assessed using SPSS version 20.0 (IBM Corp., Armonk, NY, USA). A p-value <0.05 was considered statistically significant.

\section{RESULTS}

\section{Baseline characteristics}

A total of 256 patients with CHC who were treated with pegIFN plus ribavirin were recruited. All patients were treatmentnaive. However, 66 patients were excluded based on our exclusion criteria. Finally, 190 patients were included in the analyse (Fig. 1). The baseline characteristics of our study population are summarized in Table 1. The mean age (84 men and 106 women) was 54.1 years. Liver cirrhosis was identified in 85 patients (44.7\%), and all patients had well-preserved liver function of Child-Pugh class A. HCV genotype 1 was present in 109 patients (57.4\%). The mean LS value at SVR was $7.1 \pm 5.4 \mathrm{kPa}$.

\section{LRE development}

During the follow-up period (median, 43.0 months; range,

Table 2. Liver-Related Events ( $\mathrm{n}=10)$

\begin{tabular}{ll}
\hline \multicolumn{1}{c}{ Variable } & \multicolumn{1}{c}{ Value } \\
\hline Follow-up period after SVR, mo & $43.0(6.0-120.0)$ \\
Time to LRE development after SVR, mo & $22.8(8.4-71.1)$ \\
Type of LREs & \\
Decompensation & $1(10.0)$ \\
Hepatocellular carcinoma & $8(80.0)$ \\
Liver-related death & $1(10.0)$ \\
\hline
\end{tabular}

Data are presented as median (range) or number (\%).

SVR, sustained virological response; LRE, liver-related events. 
6.0 to 120.0 months), 10 patients (5.3\%) experienced LRE development (HCC in eight patients, ascitic decompensation in one patient, and liver-related mortality in one patient) (Table 2). The cumulative incidences of LRE development at 1, 2, and 3 years were $0.5 \%, 1.1 \%$, and $2.1 \%$, respectively (an annual incidence

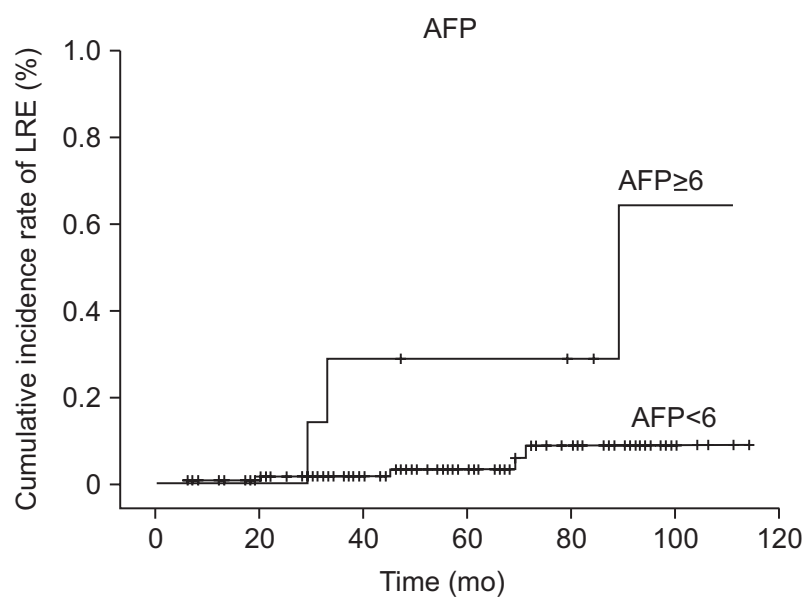

Fig. 2. Cumulative incidence rates of liver-related event (LRE) development. The cumulative incidence rates of LRE development at 1, 2, and 3 years were $0.5 \%, 1.1 \%$, and $2.1 \%$, respectively. AFP, $\alpha$-fetoprotein. rate of 3.90/1,000 person-years [PYs]) (Fig. 2). The median time to LRE occurrence after SVR was 22.8 months (range, 8.4 to 71.1 months) (Table 2). The first HCC was diagnosed at 8.4 months after achieving SVR; this patient exhibited an LS value of $14.1 \mathrm{kPa}$ at SVR and had single HCC with $1.3 \mathrm{~cm}$ in diameter. The median time from SVR to HCC diagnosis was 19.4 months (range, 8.4 to 52.7 months); these patients had median LS values of $7.8 \mathrm{kPa}$ (range, 6.1 to $26.6 \mathrm{kPa}$ ) at SVR. Ascitic decompensation developed in one patient, which was diagnosed at 30.7 months after SVR (LS value, $25.0 \mathrm{kPa}$ at SVR). Six of the eight patients with HCC had clinical liver cirrhosis.

\section{Comparison between patients with and without develop- ment of LRE after SVR}

The clinical characteristics of patients with and without LRE development are shown in Table 3. LS values were significantly higher in patients with LRE development than in those without (mean, $16.6 \mathrm{kPa}$ vs $6.8 \mathrm{kPa}, \mathrm{p}<0.001$ ). Age, male gender, ALT level, AFP level, and the proportion of liver cirrhosis were also significantly higher in patients with LRE development than those without (all $\mathrm{p}<0.05$ ). The risk of LRE development was statistically similar according to HCV genotype (1 vs 2 or 3 ) and the type of antiviral agents (peg-IFN- $\alpha 2 \mathrm{a}$ or $\alpha 2 \mathrm{~b}$ ).

Table 3. Comparison between Patients with and without Liver-Related Event Development

\begin{tabular}{|c|c|c|c|}
\hline Variable & $\begin{array}{l}\text { Patients with LRE } \\
(\mathrm{n}=10,5.3 \%)\end{array}$ & $\begin{array}{l}\text { Patients without LRE } \\
\quad(\mathrm{n}=180,94.7 \%)\end{array}$ & $\mathrm{p}$-value \\
\hline \multicolumn{4}{|l|}{ Demographic variable } \\
\hline Age, yr & $66.8 \pm 6.3$ & $53.4 \pm 11.2$ & 0.024 \\
\hline Male sex & $8(80.0)$ & $76(42.2)$ & $<0.001$ \\
\hline Body mass index, $\mathrm{kg} / \mathrm{m}^{2}$ & $23.6 \pm 1.9$ & $23.6 \pm 3.2$ & NS \\
\hline Diabetes mellitus & $2(20.0)$ & $29(16.1)$ & NS \\
\hline Hypertension & $1(10.0)$ & $34(18.9)$ & NS \\
\hline \multicolumn{4}{|l|}{ Treatment variable } \\
\hline HCV genotype 1 & $7(70.0)$ & $102(56.7)$ & NS \\
\hline Peg-IFN $\alpha-2 a$ & $6(60.0)$ & $120(66.7)$ & NS \\
\hline \multicolumn{4}{|l|}{ Laboratory variable } \\
\hline Alanine aminotransferase, IU/L & $39.1 \pm 58.0$ & $19.3 \pm 7.8$ & $<0.001$ \\
\hline Serum albumin, $g / d L$ & $4.1 \pm 0.4$ & $4.4 \pm 0.4$ & NS \\
\hline Total bilirubin, $\mathrm{mg} / \mathrm{dL}$ & $0.9 \pm 0.3$ & $0.7 \pm 0.3$ & NS \\
\hline Prothrombin time, INR & $1.0 \pm 0.1$ & $0.9 \pm 01$ & NS \\
\hline$\alpha$-Fetoprotein, ng/mL & $9.7 \pm 8.8$ & $3.0 \pm 2.5$ & $<0.001$ \\
\hline Total cholesterol, mg/dL & $145.3 \pm 34.1$ & $160.0 \pm 42.3$ & NS \\
\hline Clinical liver cirrhosis & $8(80.0)$ & $77(42.8)$ & 0.017 \\
\hline Child-Pugh score 5 & $10(100.0)$ & $179(99.4)$ & 0.005 \\
\hline \multicolumn{4}{|l|}{ Liver stiffness measurement } \\
\hline Liver stiffness values, $\mathrm{kPa}$ & $16.6 \pm 6.4$ & $6.8 \pm 5.2$ & $<0.001$ \\
\hline
\end{tabular}

Data are presented as mean \pm SD or number $(\%)$.

LRE, liver-related event; NS, not significant; HCV, hepatitis C virus; peg-IFN, pegylated interferon; INR, international normalized ratio; kPa, kilopascal. 


\section{Risk factors for LRE development}

In univariate Cox regression analyses, age, AFP level, and LS values were selected as significant predictors for LRE development (Table 4). The time-dependent AUROC value for age, AFP level, and LS values were 0.877 (95\% confidence interval [CI], 0.781 to 0.973 ), 0.762 (95\% CI, 0.556 to 0.969 ), and 0.920 (95\% CI, 0.843 to 0.996$)$, respectively. The cutoff values for age ( $\geq 65$ years vs $<65$ years; sensitivity, 80.0\%; specificity, 85.2\%), AFP level ( $\geq 6.0 \mathrm{ng} / \mathrm{mL}$ vs $<6.0 \mathrm{ng} / \mathrm{mL}$; sensitivity, $80.0 \%$; specificity, $85.1 \%$ ), and LS values ( $\geq 7.0 \mathrm{kPa}$ vs $<7.0 \mathrm{kPa}$; sensitivity, $80.0 \%$; specificity, 88.5\%) were calculated to maximize their diagnostic accuracy.

In subsequent multivariate analysis, age $\geq 65$ years, AFP level $\geq 6.0 \mathrm{ng} / \mathrm{mL}$, and LS value $\geq 7.0 \mathrm{kPa}$ independently predicted LRE development with a hazard ratio (HR) of 8.230 (95\% CI, 1.323 to $51.187 ; p=0.024), 11.363$ (95\% CI, 1.348 to 95.793; $p=0.025$ ), and 9.472 (95\% CI, 1.018 to $88.126 ; \mathrm{p}=0.048)$, respectively (Table 4). The cumulative incidence rates of LRE development increased significantly in patients with older age, higher AFP level, and higher LS values at SVR (log-rank test, all $\mathrm{p}<0.05$ ) (Fig. 3). The 3-year cumulative incidence rate of LRE development was significantly higher in older patients $(24.8 \%$ in patients aged $\geq 65$ years vs $1.4 \%$ in those aged $<65$ years; HR, 18.500 ;
95\% CI, 3.750 to 91.257; $\mathrm{p}<0.001$ ), those with higher AFP leve (28.6\% in patients with AFP $\geq 6.0 \mathrm{ng} / \mathrm{mL}$ vs $2.4 \%$ in those with AFP level <6.0 ng/mL; HR, 26.522; 95\% CI, 4.757 to 144.539 ; $\mathrm{p}<0.001)$, and those with higher LS values $(26.2 \%$ in patients with LS values $\geq 7.0 \mathrm{kPa}$ vs $0.9 \%$ in those with LS values $<7.0$ $\mathrm{kPa}$; HR, 24.562; 95\% CI, 3.031 to 199.039; $\mathrm{p}=0.003$ ).

\section{DISCUSSION}

The achievement of SVR is considered the single most important predictor for prognostication of disease progression in patients with $\mathrm{CHC}^{2-4}$ Nowadays, although increasing numbers of patients achieve SVR with the introduction of direct-acting antivirals (DAAs) such as telaprevir or boceprevir, ${ }^{20}$ there still exists a sustained risk of LRE development, such as HCC, hepatic decompensation, or liver-related death., ${ }^{5,21}$ This is mainly due to residual advanced fibrosis even after the regression of cirrhosis by successful treatment represented as SVR. However, the clinical implication of residual fibrotic burden in patients who achieved SVR has not been sufficiently investigated. Only a few studies have emphasized that patients with regressed cirrhosis had lower incidence of LREs, ${ }^{10}$ because the assessment of regression of cirrhosis at SVR by LB is not clinically feasible due to its potential invasiveness. Therefore, we evaluated the

Table 4. Independent Factors Associated with Liver-Related Event Development after Sustained Virological Response

\begin{tabular}{|c|c|c|c|}
\hline \multirow{2}{*}{ Variable } & \multirow{2}{*}{$\begin{array}{c}\text { Univariate } \\
\mathrm{p} \text {-value }\end{array}$} & \multicolumn{2}{|c|}{ Multivariate } \\
\hline & & Hazard ratio $(95 \% \mathrm{CI})$ & $\mathrm{p}$-value \\
\hline \multicolumn{4}{|l|}{ Demographic variables } \\
\hline Age $\geq 65$ yr (vs $<65$ yr) & $<0.001$ & $8.230(1.323-51.187)$ & 0.024 \\
\hline Male sex & NS & - & - \\
\hline Body mass index, $\mathrm{kg} / \mathrm{m}^{2}$ & NS & - & - \\
\hline Diabetes mellitus & NS & - & - \\
\hline Hypertension & NS & - & - \\
\hline \multicolumn{4}{|l|}{ Treatment variable } \\
\hline Genotype 1 (vs 2 or 3 ) & NS & - & - \\
\hline peg-INF $\alpha-2 a$ (vs 2b) & NS & - & - \\
\hline \multicolumn{4}{|l|}{ Laboratory variable } \\
\hline Alanine aminotransferase & NS & - & - \\
\hline Serum albumin, $g / d L$ & NS & - & - \\
\hline Total bilirubin, mg/dL & NS & - & - \\
\hline Prothrombin time, INR & NS & - & - \\
\hline$\alpha$-Fetoprotein $\geq 6.0 \mathrm{ng} / \mathrm{mL}$ (vs $<6.0 \mathrm{ng} / \mathrm{mL}$ ) & $<0.001$ & $11.363(1.348-95.793)$ & 0.025 \\
\hline Total cholesterol, mg/dL & NS & - & - \\
\hline Clinical liver cirrhosis & NS & - & - \\
\hline Child-Pugh score & NS & - & - \\
\hline \multicolumn{4}{|l|}{ Liver stiffness measurement } \\
\hline Liver stiffness values $\geq 7.0 \mathrm{kPa}$ (vs $<7.0 \mathrm{kPa}$ ) & 0.003 & $9.472(1.018-88.126)$ & 0.048 \\
\hline
\end{tabular}

CI, confidence interval; NS, not significant; peg-IFN, pegylated interferon; INR, international normalized ratio; kPa, kilopascal. 

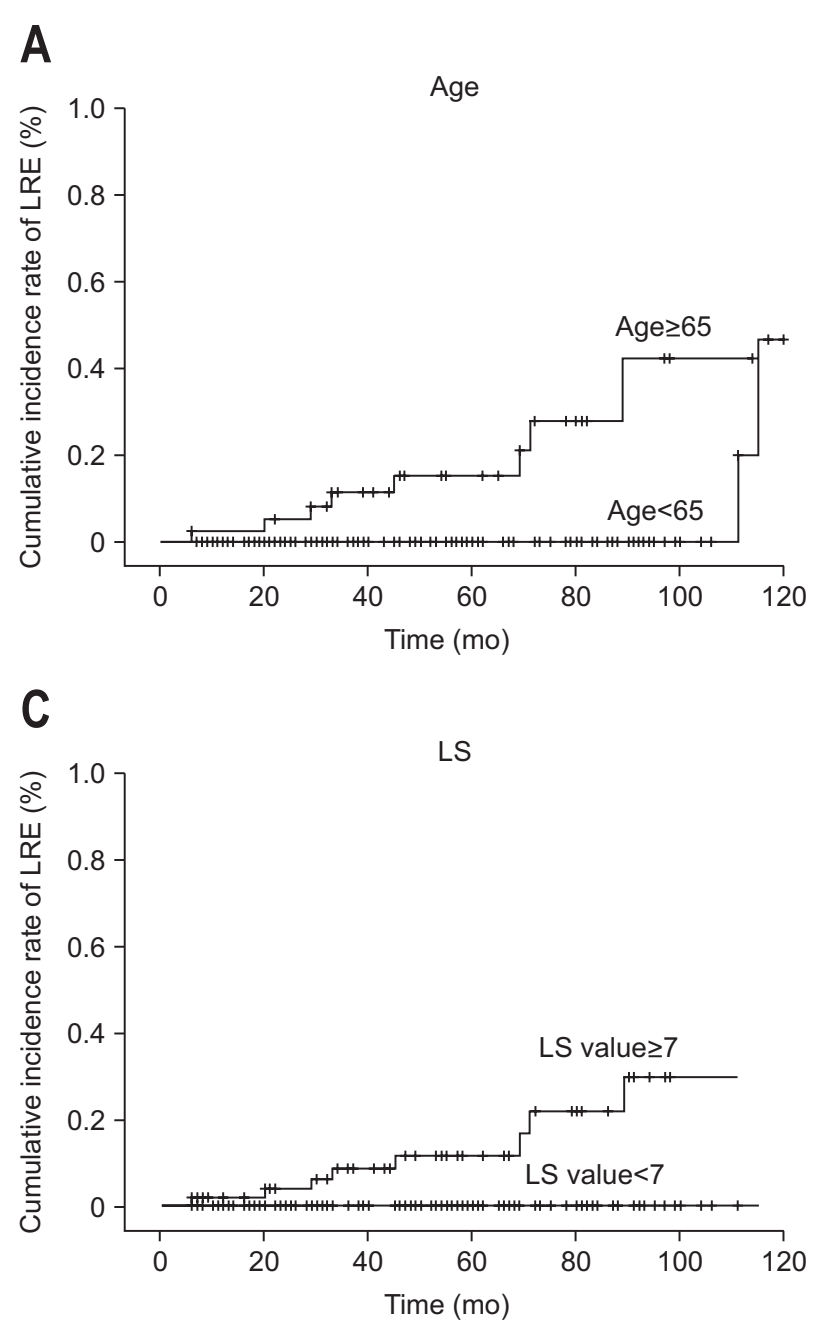

residual fibrotic burden in patients at SVR using TE, which has been well validated for assessing the degree of liver fibrosis in patients with chronic viral hepatitis. Our results show that the LS value at SVR can independently predict future LRE development.

In our study, a total of ten LREs developed (eight HCC, one ascetic decompensation and liver-related mortality). The HCC incidence rate was 0.7 per $100 \mathrm{PYs}$, which is consistent with results from previous studies reporting the reduced but persistent risk of HCC incidence as approximately 1 per 100 PYs after SVR achievement. ${ }^{5,22}$ Similar to a previous study by Aleman et al., ${ }^{5}$ which showed the possibility of delayed HCC development after SVR, one patient in our cohort experienced HCC development at 71 months after SVR. All these observations indicate that the risk of HCC development, albeit minimal, can last for a prolonged time after SVR achievement and highlight the importance of long-term periodic surveillance for HCC in spite of SVR achievement. In addition, the incidence rate of hepatic decompensation was also low, similar to other previous studies, ${ }^{2,5}$ but developed in one patient after SVR in our cohort.

Interestingly, three out of eight patients who developed HCC

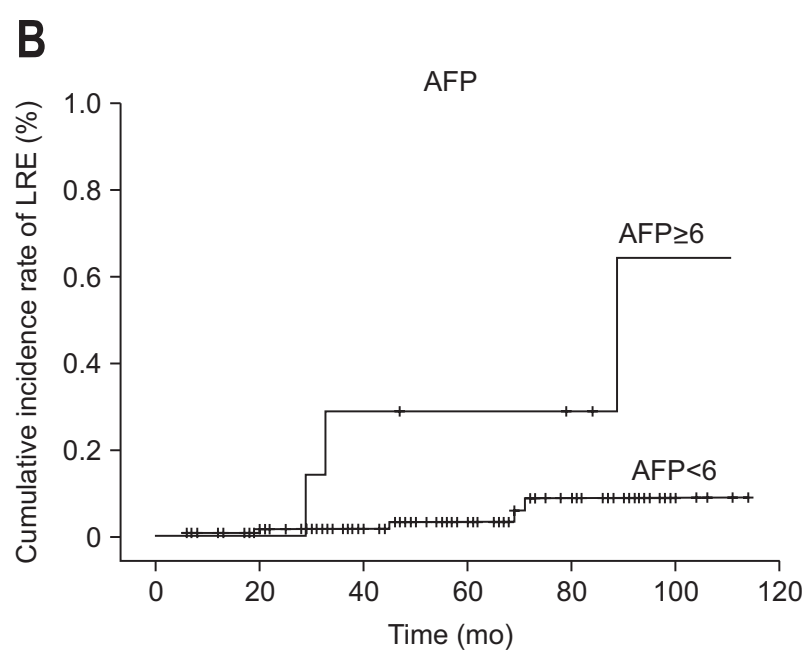

Fig. 3. Cumulative incidence rates of liver-related event (LRE) development based on stratified age and liver stiffness values. The cumulative incidence rates of LRE development increased significantly in older patients (A), those with higher $\alpha$-fetoprotein (AFP) levels (B), and those with higher liver stiffness (LS) values at sustained virological response (C) (log-rank test, all $\mathrm{p}<0.05)$.

showed relatively low LS values at SVR $(7.6,7.9$, and $6.1 \mathrm{kPa}$, respectively). This is even more intriguing because two patients who showed noncirrhotic ranges of LS values (7.6 and $7.9 \mathrm{kPa}$, respectively) had clinical cirrhosis. Although the exact reason for this phenomenon is unclear, it can be explained in part by liver remodeling after SVR achievement. Because SVR results in an improvement of most histological features of cirrhosis, such as fibrosis amount, activity and stages, LS values, which have strong correlations with these histological parameters, might decrease accordingly below the cirrhotic range. ${ }^{9,23}$ In addition, liver cell regeneration, which generally happens most actively at SVR, ${ }^{17}$ might soften the texture of the liver parenchyma and thus cause lower LS values. However, because the nodular configuration can exist unchanged even after SVR, it was possible to make a diagnosis of clinical liver cirrhosis. This hypothesis can be supported by a recent study by D'Ambrosio et al., ${ }^{17}$ which showed that among patients who were predicted to have regressed cirrhosis based on the presence of LS values $<12.0$ $\mathrm{kPa}, 21 \%$ still had histological features of liver cirrhosis at the concurrent LB at SVR.

Because LS values do not represent the structure of fibrosis 
but the amount, TE may not be suitable tool for defining liver cirrhosis, especially in patients with CHC at SVR. However, it was proved through our study that the prognostic role of the LS value for predicting LRE development after SVR should not be underestimated. First, the LS value was selected as one of independent predictors for LRE development even after adjusting the influence of clinical liver cirrhosis. Second, among patients with clinical liver cirrhosis, the mean LS value of patients with LRE development $(n=8)$ was significantly higher than those of patients without LRE development $(\mathrm{n}=77)(13.7 \mathrm{kPa}$ vs $6.4 \mathrm{kPa}$, $\mathrm{p}<0.001)$.

To date, only few of studies have proposed various prognostic factors including age, AFP, or ALT level at SVR in patients with CHC. ${ }^{22,24}$ Oze et al. ${ }^{22}$ and Asahina et al. ${ }^{24}$ concluded that AFP level at SVR is an independent predictor for HCC occurrence. They explained this phenomenon by the fact that high AFP levels at SVR can indicate the proliferative activity of liver cells, which may result in hepatocarcinogenesis. Similarly, AFP level was also selected as one of independent predictors of HCC development after SVR and the calculated cutoff AFP level was strikingly same as the cutoff from a previous study by Asahina et al. $(6 \mathrm{ng} / \mathrm{mL})$. However, the study by Oze et al. ${ }^{22}$ and Asahina et al., ${ }^{24}$ did not adjust for the residual fibrotic burden, the single most important factor for HCC development, at SVR; therefore, further investigation with a large sample size and TE data will be required to validate our current results.

Our study has several strengths. To our knowledge, this is the first study that involved the LS value obtained using TE for predicting LRE development in patients with CHC who achieved SVR. In our study, patients with LS value $\geq 7.0 \mathrm{kPa}, A F P \geq 6 \mathrm{ng} /$ $\mathrm{mL}$ and age $\geq 65$ years at SVR had 9-, 11- and 8-fold higher risk for LRE development than their counterparts. Second, in this era of effective antiviral treatment including DAAs, complete viral eradication has become possible in more than 90\% of patients with CHC. ${ }^{25,26}$ Thus, the clinical implication of predicting antiviral efficacy, reflected by the achievement of SVR, has been attenuated, but it has become important to predict long-term prognosis after SVR. Measurement of the LS value at SVR can resolve this issue to a certain extent. Third, LS values at SVR when necroinflammation subsides and ALT level is normalized accordingly can be more reliable in assessing the fibrotic burden without confounding effects, because LS values at the initiation of antiviral treatment could overestimate fibrosis burden due to high ALT levels.

We are also aware of several issues which still remain unresolved. First, as LB data at SVR were not available, we could not evaluate the relationships among the residual fibrotic burden, LS values, and prognosis. The relatively small sample size, small number of LREs, and the short-term follow-up period are limitations as well. Future large-scale studies with sufficient histological data and longer follow-up periods can resolve these issues.

In conclusion, the LS value at SVR is useful for predicting
LRE development in patients with CHC who achieved SVR through peg-IFN plus ribavirin therapy. Because patients with LS values $\geq 7.0 \mathrm{kPa}$ have higher risk for LRE development, LRE surveillance strategies might be optimized according to LS values at SVR, even with complete viral eradication.

\section{CONFLICTS OF INTEREST}

No potential conflict of interest relevant to this article was reported.

\section{ACKNOWLEDGEMENTS}

This study was supported by the Liver Cirrhosis Clinical Research Center, in part by a grant from the Korea Healthcare Technology R\&D project, Ministry of Health and Welfare, Republic of Korea (number: HI10C2020). The funders had no role in study design, data collection and analysis, decision to publish, or preparation of the manuscript.

Author contributions: conception: Seung Up Kim; study design: Hye Won Lee, Young Eun Chon, and Seung Up Kim; participation in patient management and data collection: Kyu Sik Jung, Beom Kyung Kim, Jun Yong Park, Do young Kim, Sang Hoon Ahn, Young Nyun Park, and Kwang-Hyub Han; contribution to the data acquisition, responsibility for writing the paper and statistical analysis: Hye Won Lee, Young Eun Chon and Seung Up Kim. All authors reviewed the paper and approved the final version.

The authors are grateful to Dong-Su Jang (Medical Illustrator, Medical Research Support Section, Yonsei University College of Medicine, Seoul, Korea) for the help with this journal.

\section{REFERENCES}

1. Morisco F, Granata R, Stroffolini T, et al. Sustained virological response: a milestone in the treatment of chronic hepatitis C. World J Gastroenterol 2013;19:2793-2798.

2. Bruno S, Crosignani A, Facciotto C, et al. Sustained virologic response prevents the development of esophageal varices in compensated, Child-Pugh class A hepatitis C virus-induced cirrhosis: a 12-year prospective follow-up study. Hepatology 2010;51:20692076

3. Fernández-Rodríguez CM, Alonso S, Martinez SM, et al. Peginterferon plus ribavirin and sustained virological response in HCVrelated cirrhosis: outcomes and factors predicting response. Am J Gastroenterol 2010;105:2164-2172.

4. Bruno S, Stroffolini T, Colombo M, et al. Sustained virological response to interferon-alpha is associated with improved outcome in HCV-related cirrhosis: a retrospective study. Hepatology 2007;45:579-587.

5. Aleman S, Rahbin N, Weiland 0, et al. A risk for hepatocellular carcinoma persists long-term after sustained virologic response in 
patients with hepatitis C-associated liver cirrhosis. Clin Infect Dis 2013;57:230-236.

6. Morgan TR, Ghany MG, Kim HY, et al. Outcome of sustained virological responders with histologically advanced chronic hepatitis $\mathrm{C}$. Hepatology 2010;52:833-844.

7. Masuzaki R, Yoshida H, Omata M. Interferon reduces the risk of hepatocellular carcinoma in hepatitis $\mathrm{C}$ virus-related chronic hepatitis/liver cirrhosis. Oncology 2010;78 Suppl 1:17-23.

8. Masuzaki R, Tateishi R, Yoshida H, et al. Prospective risk assessment for hepatocellular carcinoma development in patients with chronic hepatitis $\mathrm{C}$ by transient elastography. Hepatology 2009;49:1954-1961.

9. Toccaceli F, Laghi V, Capurso L, et al. Long-term liver histology improvement in patients with chronic hepatitis $\mathrm{C}$ and sustained response to interferon. J Viral Hepat 2003;10:126-133.

10. Mallet V, Gilgenkrantz H, Serpaggi J, et al. Brief communication: the relationship of regression of cirrhosis to outcome in chronic hepatitis C. Ann Intern Med 2008;149:399-403.

11. Castera L, Bedossa P. How to assess liver fibrosis in chronic hepatitis C: serum markers or transient elastography vs. liver biopsy? Liver Int 2011;31 Suppl 1:13-17.

12. Amorim TG, Staub GJ, Lazzarotto C, et al. Validation and comparison of simple noninvasive models for the prediction of liver fibrosis in chronic hepatitis C. Ann Hepatol 2012;11:855-861.

13. Tsochatzis EA, Gurusamy KS, Ntaoula S, Cholongitas E, Davidson $\mathrm{BR}$, Burroughs AK. Elastography for the diagnosis of severity of fibrosis in chronic liver disease: a meta-analysis of diagnostic accuracy. J Hepatol 2011;54:650-659.

14. Poynard T, Vergniol J, Ngo Y, et al. Staging chronic hepatitis C in seven categories using fibrosis biomarker (FibroTest ${ }^{\mathrm{TM}}$ ) and transient elastography (FibroScan ${ }^{\circledR}$ ). J Hepatol 2014;60:706-714.

15. Sandrin L, Fourquet B, Hasquenoph JM, et al. Transient elastography: a new noninvasive method for assessment of hepatic fibrosis. Ultrasound Med Biol 2003;29:1705-1713.

16. Castera L. Noninvasive methods to assess liver disease in patients with hepatitis B or C. Gastroenterology 2012;142:1293-1302.e4.

17. D’Ambrosio R, Aghemo A, Fraquelli M, et al. The diagnostic accuracy of Fibroscan for cirrhosis is influenced by liver morphometry in HCV patients with a sustained virological response. J Hepatol 2013;59:251-256.

18. Chon YE, Jung ES, Park JY, et al. The accuracy of noninvasive methods in predicting the development of hepatocellular carcinoma and hepatic decompensation in patients with chronic hepatitis B. J Clin Gastroenterol 2012;46:518-525.

19. Jung KS, Kim SU, Ahn SH, et al. Risk assessment of hepatitis B virus-related hepatocellular carcinoma development using liver stiffness measurement (FibroScan). Hepatology 2011;53:885-894.

20. European Association for Study of Liver. EASL Clinical Practice Guidelines: management of hepatitis C virus infection. J Hepatol 2014;60:392-420.

21. Asahina Y, Tsuchiya K, Tamaki N, et al. Effect of aging on risk for hepatocellular carcinoma in chronic hepatitis $\mathrm{C}$ virus infection. Hepatology 2010;52:518-527.

22. Oze T, Hiramatsu N, Yakushijin T, et al. Post-treatment levels of alpha-fetoprotein predict incidence of hepatocellular carcinoma after interferon therapy. Clin Gastroenterol Hepatol 2014;12:11861195.

23. Zois CD, Baltayiannis GH, Karayiannis P, Tsianos EV. Systematic review: hepatic fibrosis: regression with therapy. Aliment Pharmacol Ther 2008;28:1175-1187.

24. Asahina Y, Tsuchiya K, Nishimura T, et al. Alpha-fetoprotein levels after interferon therapy and risk of hepatocarcinogenesis in chronic hepatitis C. Hepatology 2013;58:1253-1262.

25. Bari K, Sharma P. Combination of daclatasvir and sofosbuvir for hepatitis C genotypes 1, 2, and 3. Gastroenterology 2014;147:534536.

26. Lawitz E, Mangia A, Wyles D, et al. Sofosbuvir for previously untreated chronic hepatitis C infection. N Engl J Med 2013;368:18781887. 